\title{
Micromorph thin-film silicon solar cells with transparent high-mobility hydrogenated indium oxide front electrodes
}

\author{
Corsin Battaglia, ${ }^{\text {a) }}$ Lukas Erni, Mathieu Boccard, Loris Barraud, Jordi Escarré, \\ Karin Söderström, Grégory Bugnon, Adrian Billet, Laura Ding, Matthieu Despeisse, \\ Franz-Josef Haug, Stefaan De Wolf, and Christophe Ballif \\ Ecole Polytechnique Fédérale de Lausanne (EPFL), Institute of Microengineering (IMT), \\ Photovoltaics and Thin Film Electronics Laboratory, 2000 Neuchâtel, Switzerland
}

(Received 23 March 2011; accepted 20 April 2011; published online 1 June 2011)

\begin{abstract}
We investigate the performance of hydrogenated indium oxide as a transparent front electrode for micromorph thin-film silicon solar cells on glass. Light trapping is achieved by replicating the morphology of state-of-the-art zinc oxide electrodes, known for their outstanding light trapping properties, via ultraviolet nanoimprint lithography. As a result of the high electron mobility and excellent near-infrared transparency of hydrogenated indium oxide, the short-circuit current density of the cells is improved with respect to indium tin oxide and zinc oxide electrodes. We assess the potential for further current gains by identifying remaining sources of parasitic absorption and evaluate the light trapping capacity of each electrode. We further present a method, based on nonabsorbing insulating silicon nitride electrodes, allowing one to directly relate the optical reflectance to the external quantum efficiency. Our method provides a useful experimental tool to evaluate the light trapping potential of novel photonic nanostructures by a simple optical reflectance measurement, avoiding complications with electrical cell performance. (C) 2011 American Institute of Physics. [doi:10.1063/1.3592885]
\end{abstract}

\section{INTRODUCTION}

Thin-film silicon solar cells have been identified as one of the most promising technologies to render photovoltaics, the conversion of sunlight to electricity, economically competitive with fossil-fuel technologies, as they are based on abundant, nontoxic materials and low-temperature processes. ${ }^{1,2}$ In particular micromorph tandem solar cells, ${ }^{3}$ consisting of a stack of a high-gap amorphous (a-Si:H) and a low-gap microcrystalline $(\mu \mathrm{c}-\mathrm{Si}: \mathrm{H})$ silicon solar cell on a glass substrate, have attracted a lot of interest, as the serial connection of a $\mu \mathrm{c}-\mathrm{Si}: \mathrm{H}$ bottom cell behind an a-Si:H top cell not only extends light harvesting into the near-infrared region of the solar spectrum, but also offers an advantageous impedance compared to a single junction architecture, reducing Ohmic losses in the electrodes. ${ }^{1,4,5}$

To achieve high efficiencies with thin-film silicon solar cells, the optical and electrical properties of the transparent front electrodes are decisive. ${ }^{6-17}$ Transparency and conductivity are directly interlinked via the carrier density: a large number of electrons causes strong parasitic light absorption in the near-infrared region (free carrier absorption), whereas an insufficient number of free electrons leads to heavy Ohmic losses. A smart solution for improving the transparency of the front electrode, without compromising its conductivity, is the use of high-mobility transparent conductive oxides (TCO). Increasing the carrier mobility allows one to reduce the carrier density, and with it the free carrier absorption, while maintaining the resistivity at a constant value.

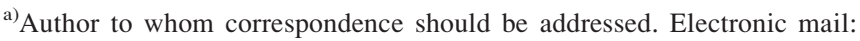
corsin.battaglia@epfl.ch,http://pvlab.epfl.ch/
}

Recently Koida et al. ${ }^{18}$ reported the development of a hydrogenated indium oxide $\operatorname{In}_{2} \mathrm{O}_{3}: \mathrm{H}(\mathrm{IOH})$ with very high mobilities at low carrier densities resulting in excellent nearinfrared transparency. Here we compare the performance of sputtered IOH with conventional sputtered indium tin oxide $\mathrm{In}_{2} \mathrm{O}_{3}-\mathrm{SnO}_{2}$ (ITO) and state-of-the-art zinc oxide $(\mathrm{ZnO})$, deposited via chemical vapor deposition, in the front electrode of micromorph silicon solar cells in superstrate $(p-i-n)$ configuration.

A comparison between IOH and ITO on $\mu \mathrm{c}-\mathrm{Si}: \mathrm{H}$ solar cells in the substrate $(n-i-p)$ configuration and on a-Si:H/ crystalline silicon heterojunction solar cells was already presented by Koida et al. in Refs. 12 and 19, respectively. Compared with the $n-i-p$ and heterojunction cell configurations investigated previously, where the front electrode serves (1) to extract current and (2) as an antireflection layer at the airsilicon interface, the front electrode of $p-i-n$ solar cells is also responsible for (3) scattering the light in order to maximize light absorption in the thin absorbing silicon layers. Traditionally light scattering for $p-i-n$ cells is implemented by exploiting either the natural, randomly oriented pyramidal texture of $\mathrm{ZnO}$ or tin oxide $\left(\mathrm{SnO}_{2}\right)$ grown via chemical vapor deposition $^{20,21}$ or the craterlike structure obtained on sputtered $\mathrm{ZnO}$ after wet-etching. ${ }^{17}$ We recently presented an alternative approach to achieve excellent light scattering in thin-film silicon solar cells: ${ }^{4,15}$ to obtain functional front electrodes with IOH and ITO, we replicated the morphology of state-of-the-art $\mathrm{ZnO}$ electrodes via ultraviolet nanoimprint lithography (UV-NIL) ${ }^{22}$ and added a thin conformal IOH and ITO layer by sputtering. Here we present an in-depth comparison of the performance between such IOH and ITO based electrodes and state-of-the-art $\mathrm{ZnO}$ electrodes in the 
micromorph tandem configuration. We further introduce insulating silicon nitride $\left(\mathrm{SiN}_{x}\right)$ electrodes, with similar refractive index as $\mathrm{IOH}$, but without free carrier absorption, to identify remaining parasitic absorption losses and relate the optical reflectance to the external quantum efficiency.

\section{EXPERIMENT}

Pyramidally textured, slightly boron-doped $\mathrm{ZnO}$ layers serving as a reference substrate for the cells and as a master for the UV-NIL replication process were grown via lowpressure chemical vapor deposition (LP-CVD) $)^{20}$ at $180{ }^{\circ} \mathrm{C}$ on $0.5 \mathrm{~mm}$ thick borosilicate glass without antireflection coating and subjected to 20 min argon plasma treatment ${ }^{23}$ to optimize the morphology for the growth of the cells.

These $\mathrm{ZnO}$ layers were then used as a master for our recently developed high-fidelity UV-NIL replication process described in detail in Refs. 22 and 24. Subsequently either IOH (or ITO) was sputtered on the transparent replicas with a $\mathrm{rf}(\mathrm{dc})$ power of $800 \mathrm{~W}(1000 \mathrm{~W})$ in an argon atmosphere at a total pressure of $5 \times 10^{-3}$ Torr $\left(6 \times 10^{-3}\right.$ Torr $)$ including $0.2 \%(2 \%)$ of oxygen. For $\mathrm{IOH}$, we additionally dosed a small flow of water vapor via a needle valve into the deposition chamber resulting in a water partial pressure of $7 \times 10^{-6}$ Torr. IOH and ITO layers were covered by a thin sputtered aluminum-doped $\mathrm{ZnO}$ layer of thickness $t=20 \mathrm{~nm}$ which serves as a protective barrier layer against the hydrogen-rich plasma during the subsequent cell deposition. ${ }^{25-27}$ This $\mathrm{ZnO}$ layer influences neither the optical nor the electrical measurements on the IOH and ITO films observably, as its much lower carrier density renders it very transparent and much more resistive than $\mathrm{IOH}$ and ITO. As $\mathrm{ZnO}$ also has a similar refractive index as $\mathrm{IOH}$ and ITO, no signficant reflection occurs at the $\mathrm{IOH}-\mathrm{ZnO}$ and ITO-ZnO interface.

After deposition, IOH requires an annealing step at $200^{\circ} \mathrm{C}$, which transforms the initially amorphous $\mathrm{IOH}$ film into a polycrystalline film leading to a reduction of charge carriers and a spectacular increase of the carrier mobility to values above $100 \mathrm{~cm}^{2} / \mathrm{V} \cdot \mathrm{s}$. This solid-phase crystallization process was described in detail in Ref. 28. ITO, upon annealing, behaves quite differently, as it is already in a polycrystalline form after sputtering. Its carrier density increases by a factor of 2 to 3 , whereas the mobility is only very slightly improved (10-20\%). In this work IOH and ITO films were not annealed in a separate annealing step, but annealing took place during the deposition of the micromorph cells deposited at $200{ }^{\circ} \mathrm{C}$. We find that the dynamic evolution of the carrier density and mobility during annealing is strongly dependent on the oxygen partial pressure during sputtering, which was optimized accordingly. Going to a higher oxygen partial pressure of $0.4 \%$ or $0.8 \%$ during $\mathrm{IOH}$ deposition, the mobility upon annealing jumps very quickly to high values, but degrades when annealing is continued. When using only $0.2 \%$ of oxygen, $\mathrm{IOH}$ shows a gradual increase in mobility over annealing time. For ITO, the oxygen partial pressure allows one to tune the carrier density and its evolution during annealing.

Alternatively to $\mathrm{IOH}$ and ITO, insulating $\mathrm{SiN}_{x}$ layers were deposited on the replicas using plasma-enhanced chem- ical vapor deposition (PE-CVD) using $\mathrm{SiH}_{4}, \mathrm{NH}_{3}$, and $\mathrm{H}_{2}$ at a pressure of $75 \times 10^{-3}$ Torr at $200{ }^{\circ} \mathrm{C}$. The refractive index of $\mathrm{SiN}_{x}$, as measured by spectroscopic ellipsometry, was adjusted by modifying the $\mathrm{NH}_{3} / \mathrm{SiH}_{4}$ gas flux ratio, so as to obtain a refractive index comparable to $\mathrm{IOH}$.

Micromorph $p-i-n$ silicon solar cells of size $5 \times 5 \mathrm{~mm}^{2}$ were deposited by PE-CVD in an industrial KAI reactor. The micromorph tandem cells consist of an a-Si:H top cell with intrinsic layer thickness of $250 \mathrm{~nm}$ and a $\mu \mathrm{c}-\mathrm{Si}: \mathrm{H}$ bottom cell with intrinsic layer thickness of $1.1 \mu \mathrm{m}$. A resistive $\mathrm{SiO}_{x}$ interlayer as described in Refs. 29 and 30 was incorporated between the amorphous and microcrystalline subcells to limit undesired local current drains caused by the roughness of the substrate. This layer simultaneously serves as an intermediate reflector layer to boost the absorption in the amorphous top cell. ${ }^{31}$ All cells (except where explicitly stated) carry a LP-CVD $\mathrm{ZnO}$ back electrode deposited as described above, but without the plasma treatment. A white diffuse dielectric back reflector was mounted behind the back electrode for characterization.

External quantum efficiencies $(E Q E)$ of the a-Si:H top and $\mu \mathrm{c}-\mathrm{Si}: \mathrm{H}$ bottom cells $\left(E Q E_{\text {top }}\right.$ and $\left.E Q E_{\text {bot }}\right)$ were measured under red and blue bias light illumination, respectively. The corresponding short-circuit current densities $J_{s c}^{t o p}$ and $J_{s c}^{b o t}$ are calculated from the $E Q E$ curves by convolution with the photon flux of the AM1.5 solar spectrum. The current density-voltage $(J(V))$ characteristics were measured using a dual lamp sun simulator in standard test conditions $\left(25^{\circ} \mathrm{C}\right.$, AM $1.5_{g}, 1000 \mathrm{~W} / \mathrm{m}^{2}$ ) and normalized by the $J_{s c}$ value of the current-limiting cell from the $E Q E$ measurement.

Optical reflectance $R$ and transmittance $T$ measurements were carried out on a photospectrometer equipped with an integrating sphere. Absorptance $A$ was derived via the relation $A=1-R-T$. The absorptance of the rough $\mathrm{ZnO}$ layer was measured with a $\mathrm{CH}_{2} \mathrm{I}_{2}$ index matching liquid, with negligible absorption in the spectral range of interest to avoid light trapping in the $\mathrm{ZnO}$ layer and light losses through scattering out of the integrating sphere. Absorptance of IOH and ITO was measured directly by sputtering the layers on flat glass substrates and subsequent annealing at $200{ }^{\circ} \mathrm{C}$. Optical measurements on the cells were carried out on a cell area of $15 \times 15$ $\mathrm{mm}^{2}$ to get a satisfactory signal-to-noise ratio. Carrier density $n$, mobility $\mu$, and resistivity $\rho$ of IOH, ITO, and $\mathrm{ZnO}$ were determined via Hall and four-point probe measurements.

\section{RESULTS AND DISCUSSION}

Table I compares the electrical characteristics of the TCOs deposited on flat glass substrates after annealing. IOH exhibits by far the highest mobility. However, as a result of the relatively low carrier density compared with ITO, it is more resistive than the ITO layer. When deposited on the rough replicated substrates, which exhibit an increased surface area of about $30 \%$ with respect to the flat glass substrates, the effective film thickness is reduced to about 110 $\mathrm{nm}$. This also leads to a substantial increase in sheet resistance (values in parentheses in Table I). For completeness, Table I lists also the electrical properties of LP-CVD $\mathrm{ZnO}$, which serves as a state-of-the-art reference substrate for this study. 
TABLE I. Electrical characteristics of TCO layers on flat glass, values in parenthesis are for layers on replicated rough substrates.

\begin{tabular}{lccccc}
\hline \hline TCO & $\begin{array}{c}\mathrm{n} \\
{\left[\mathrm{cm}^{-3}\right]}\end{array}$ & $\begin{array}{c}\mu \\
{\left[\mathrm{cm}^{2} / \mathrm{V} \cdot \mathrm{s}\right]}\end{array}$ & $\begin{array}{c}\rho \\
{[\Omega \cdot \mathrm{cm}]}\end{array}$ & $\begin{array}{c}\mathrm{t} \\
{[\mathrm{nm}]}\end{array}$ & $\begin{array}{c}\mathrm{R}_{\mathrm{sh}} \\
{\left[\Omega_{\square}\right]}\end{array}$ \\
\hline IOH & $1.1 \times 10^{20}$ & 104 & $5 \times 10^{-4}$ & $135(110)$ & $37(45)$ \\
ITO & $7.0 \times 10^{20}$ & 26 & $3 \times 10^{-4}$ & $135(110)$ & $26(32)$ \\
ZnO & $4 \times 10^{19}$ & 37 & $4 \times 10^{-3}$ & 4800 & 8 \\
\hline \hline
\end{tabular}

In Fig. 1 we present absorptance measurements of the TCOs. In the visible part of the spectrum up to a wavelength of $1250 \mathrm{~nm}$, the absorptance of IOH remains remarkably low $(<1 \%)$. Below $400 \mathrm{~nm}$, absorptance increases rapidly due to transitions across the bandgap of IOH. A similar behavior is observed for ITO close to the bandgap. Compared with IOH, ITO exhibits a strong absorptance tail above $800 \mathrm{~nm}$ due to its high free carrier density and a generally higher absorptance across the full visible range of the spectrum. Although $40 \times$ thicker than $\mathrm{IOH}$ and ITO, $\mathrm{ZnO}$ remains very transparent above $800 \mathrm{~nm}$ due to its very low carrier density. In the visible part, the absorptance is somewhat higher than for ITO and increases sharply below $420 \mathrm{~nm}$, as the bandgap of $\mathrm{ZnO}$ is smaller than for IOH and ITO.

We now turn to the results of the micromorph cells shown in Fig. 2, where we present external quantum efficiency measurements. The amorphous top cell absorbs the blue and green part of the solar spectrum between $350 \mathrm{~nm}$ and $800 \mathrm{~nm}$, while the microcrystalline bottom cell absorbs the red and near-infrared part from $500 \mathrm{~nm}$ to $1100 \mathrm{~nm}$. We also include optical reflectance $R$ measurements (in the form $1-R)$ in Fig. 2. The advantage of this way of presenting the cell data is that the area between $1-R$ and the total external quantum efficiency $E Q E_{\text {tot }}\left(=E Q E_{\text {top }}+E Q E_{\text {bot }}\right)$ represents parasitic absorption due to either absorption in the electrodes or the doped silicon layers (assuming negligible carrier collection losses). For thicker glass substrates, the amount of light escaping through the sides of the glass may also become significant, but for the thickness of the glass substrates chosen for this study, this effect is negligible.

We first discuss the results for the amorphous top cell, in which most of the blue and green light is efficiently absorbed during the first pass through the cell, because the

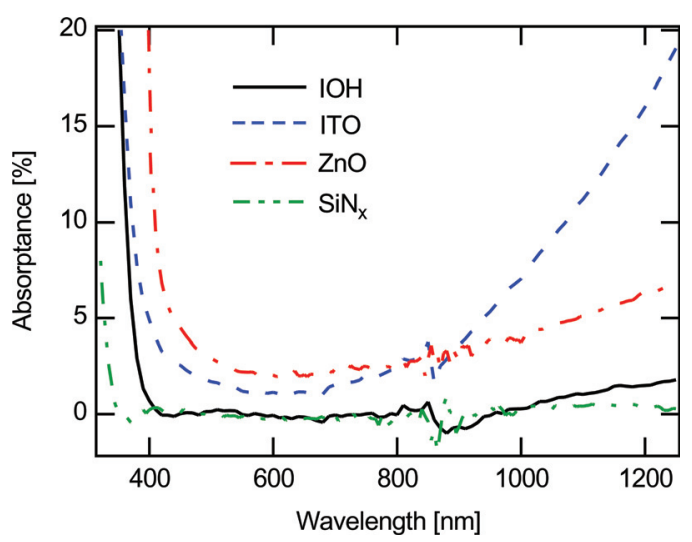

FIG. 1. (Color online) Absorptance measurements for IOH, ITO, $\mathrm{ZnO}$, and $\mathrm{SiN}_{x}$.

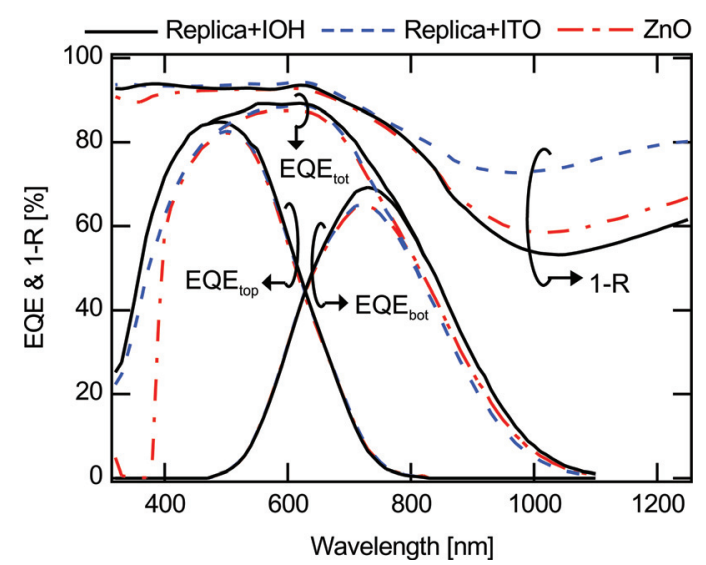

FIG. 2. (Color online) External quantum efficiencies $E Q E$ and optical reflectance $1-R$ measurements of micromorph solar cells on IOH and ITO on the replicated $\mathrm{ZnO}$ morphology and the master $\mathrm{ZnO}$.

absorption coefficient of amorphous silicon at small wavelengths is high. Here the nanotexturation serves to reduce reflections at the interfaces as the refractive index changes gradually across a nanotextured interface. This method is quite efficient as the reflectance of the total cell stack is reduced to $6-7 \%$ in the spectral range of the top cell. This value includes the $4 \%$ Fresnel reflection at the flat air-glass interface, which could be eliminated using a standard antireflection coating. The remaining $2-3 \%$ residual reflectance comes from the interface between glass (or UV-lacquer, which behaves optically like glass) and TCO and the TCOsilicon interface, which, if flat, would give $13 \%$ of combined first-order Fresnel reflection.

From inspection of the EQE measurements in Fig. 2, we see that the top cell on $\mathrm{IOH}$ exhibits the best spectral response. A gain in $J_{s c}^{t o p}$ of $0.5 \mathrm{~mA} / \mathrm{cm}^{2}$ and even $1 \mathrm{~mA} / \mathrm{cm}^{2}$ compared with the top cells on ITO and $\mathrm{ZnO}$, respectively, is observed (see Table II). Because the difference in total reflectance of the full cell stack on IOH and ITO in this spectral range does not exceed $1 \%$, most of the current gain in the top cell can be attributed to reduced parasitic absorption in the front electrode. Compared with the cell on ITO, the cell on $\mathrm{IOH}$ exhibits significantly less parasitic absorption, resulting in a higher top cell current. This observation is consistent with the absorptance measurements in Fig. 1. The difference in current when compared to $\mathrm{ZnO}$ is due to the smaller bandgap of $\mathrm{ZnO}$ with respect to $\mathrm{IOH}$ and ITO.

Focusing now on the $E Q E$ of the microcrystalline bottom cell, we observe that the cell on $\mathrm{IOH}$ again shows the highest response, which is in agreement with the low absorptance of $\mathrm{IOH}$. The reduction of free carrier absorption accounts for a massive gain of $1.2 \mathrm{~mA} / \mathrm{cm}^{2}$ compared to the cell on ITO and of $0.9 \mathrm{~mA} / \mathrm{cm}^{2}$ compared to the cell on $\mathrm{ZnO}$, as can be seen from Table II. Owing to the low absorption coefficient of silicon in the near-infrared and the efficient light scattering scheme provided by the nanotextured interfaces, the light passes multiple times through the layers. While light absorbed in the silicon absorber layer is converted to current, a significant amount of light does not contribute to current generation, as it is absorbed in the electrodes and the doped silicon layers. Reducing the parasitic absorption in the 
TABLE II. Short current densities and electrical properties of $p$ - $i$ - $n$ micromorph solar cells fabricated on different superstrates.

\begin{tabular}{|c|c|c|c|c|c|c|c|}
\hline Superstrate & $\begin{array}{c}J_{s c}^{t o t} \\
{\left[\mathrm{~mA} / \mathrm{cm}^{2}\right]}\end{array}$ & $\begin{array}{c}J_{s c}^{\text {top }} \\
{\left[\mathrm{mA} / \mathrm{cm}^{2}\right]}\end{array}$ & $\begin{array}{c}J_{s c}^{b o t} \\
{\left[\mathrm{~mA} / \mathrm{cm}^{2}\right]}\end{array}$ & $\begin{array}{c}\tilde{J}_{s c}^{b o t} \\
{\left[\mathrm{~mA} / \mathrm{cm}^{2}\right]}\end{array}$ & $\begin{array}{c}\mathrm{V}_{\mathrm{oc}} \\
{[\mathrm{mV}]}\end{array}$ & $\begin{array}{l}\mathrm{FF} \\
{[\%]}\end{array}$ & $\begin{array}{c}\text { Efficiency } \\
{[\%]}\end{array}$ \\
\hline replica $+\mathrm{IOH}$ & 25.9 & 12.9 & 13.0 & 15.7 & 1359 & 68.7 & 12.0 \\
\hline replica + ITO & 24.2 & 12.4 & 11.8 & 15.8 & 1362 & 69.5 & 11.2 \\
\hline $\mathrm{ZnO}$ & 24.0 & 11.9 & 12.1 & 15.4 & 1385 & 72.6 & 12.0 \\
\hline $\mathrm{ZnO}+\mathrm{IOH}$ & 24.2 & 12.1 & 12.1 & 15.5 & 1365 & 70.7 & 11.7 \\
\hline $\mathrm{ZnO}+\mathrm{ITO}$ & 22.8 & 12.0 & 10.8 & 15.5 & 1375 & 71.8 & 10.6 \\
\hline
\end{tabular}

near-infrared by improving the transparency of the electrodes and the doped layers not only leads to an increase of the external quantum efficiency, but also to increased reflection of light out of the cell. This is clearly seen in the reflectance measurements in Fig. 2.

To compare light scattering in the absence of parasitic absorption between the three cells, we rescale the $E Q E$ data as described in Refs. 32, 6, and 33. In the case of ideal carrier collection, we have $E Q E+R+A=1$, where $A$ represents the parasitic absorption of the cell (graphically given by the area between $E Q E$ and $1-R$ in Fig. 2). Assuming zero parasitic absorption, we can define normalized quantities $E \tilde{Q} E$ and $\tilde{R}$ satisfying $E \tilde{Q} E+\tilde{R}=1$. This normalization is achieved by splitting $A$ equitably between $E Q E$ and $R$ : $E \tilde{Q} E=E Q E /(1-A)$ and $\tilde{R}=R /(1-A)$. Normalized $E \tilde{Q} E s$ are shown in Fig. 3 for the microcrystalline bottom cell. All three curves practically coincide, confirming that light scattering is very similar in the three cases.

From the normalized $E \tilde{Q} E$, we are now able to extract normalized bottom cell short-circuit current densities $\tilde{J}_{s c}^{b o t}$, which represent the current densities that would be measured in the absence of parasitic absorption in the electrodes and the doped layers. It is important to keep in mind that these values are optically ideal values which will be difficult to achieve, as one will hardly be able to fully eliminate parasitic absorption in the electrodes and the doped layers, while maintaining acceptable electrical device performance. Inspection of the $\tilde{J}_{s c}^{b o t}$ values in Table II reveals that for the two cells on the replica, we obtain a similar but slightly higher value than for the cell on the $\mathrm{ZnO}$ electrode. This is

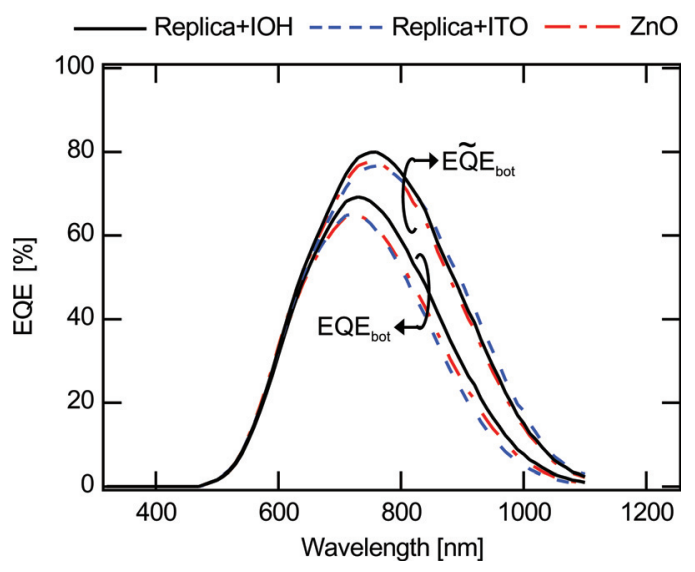

FIG. 3. (Color online) Normalized external quantum efficiencies $E \tilde{Q} E_{\text {bot }}$ of the bottom cells of the micromorph tandems. For convenience the untreated $E Q E_{\text {bot }}$ measurements of Fig. 2 are also shown. possibly a consequence of the slightly stronger light scattering due to the higher refractive index contrast of the replica at the scattering interface (see Ref. 15 for more details).

In a detailed previous study ${ }^{15,22}$ we demonstrated the high fidelity of our replication process. However, the addition of the sputtered IOH or ITO layer, although nicely conformal as seen in scanning electron microscope images on focused ion beam cuts (see Fig. 1 in Ref. 4), could lead to modifications in the light trapping efficiency, as the TCOsilicon interface is slightly smoothed. To check this, we further deposited a cell on a $\mathrm{ZnO}$ substrate with an additional IOH or ITO layer. As can be seen from Fig. 4 as well as from Table II, the bottom cell with the additional IOH layer on top of the $\mathrm{ZnO}$ substrate delivers practically the same current as the bottom cell on the bare $\mathrm{ZnO}$. This shows that light trapping is not deteriorated by the sputtered film. We further conclude that the free carrier absorption of $\mathrm{IOH}$ does not contribute significant additional parasitic absorption to the absorption of the bare $\mathrm{ZnO}$. The effect of the absorption of the additional $\mathrm{IOH}$ layer on $\mathrm{ZnO}$, although not observable in the $E Q E$ measurement, is, however, visible in the reflectance measurements in Fig. 4, where slightly less light is reflected out of the cell, when the $\mathrm{IOH}$ layer is added on top of the $\mathrm{ZnO}$ electrode. In contrast, the bottom cell on the $\mathrm{ZnO}$ electrode covered by the ITO layer suffers from massive additional parasitic absorption losses, leading to a reduction in current of $1.3 \mathrm{~mA} / \mathrm{cm}^{2}$ accompanied by a clear reduction of the reflectance out of the cell in the near-infrared part.

By comparing the resulting bottom cell currents obtained on the bare $\mathrm{ZnO}$ and the ITO-covered $\mathrm{ZnO}$, we can

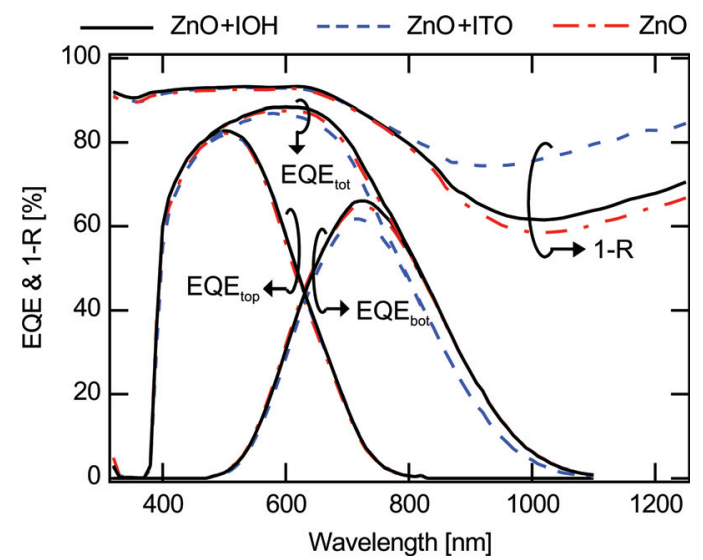

FIG. 4. (Color online) External quantum efficiencies $E Q E$ and optical reflectance $1-R$ measurements of micromorph solar cells on either $\mathrm{IOH}$ or ITO on top of $\mathrm{ZnO}$. For ease of comparison the measurements on the bare $\mathrm{ZnO}$ substrate of Fig. 2 are shown again. 
further estimate, analogously as in our previous work, ${ }^{15}$ that $1.3 \mathrm{~mA} / \mathrm{cm}^{2}$ in bottom cell current could be gained by avoiding free carrier absorption in the front electrode. Within the experimental accuracy, this value agrees with the $1.2 \mathrm{~mA} / \mathrm{cm}^{2}$ current gain, which we observe when replacing the ITO on the replica by $\mathrm{IOH}$ and validates our crude estimation.

So far we have only considered the front electrodes. A straightforward way to reduce free carrier absorption in the cell with the $\mathrm{IOH}$ front contact further is to replace the $\mathrm{ZnO}$ back contact by an $\mathrm{IOH}$ back contact. Although this leads to a significant increase of the cell reflectance (see Fig. 5), confirming the reduction in parasitic absorption, we observe only a small additional gain of $0.2 \mathrm{~mA} / \mathrm{cm}^{2}$ in bottom cell current (EQE not shown).

To further illuminate the origins of parasitic absorption in micromorph cells, we replaced the $\mathrm{IOH}$ front and back electrodes by a highly transparent, but insulating, $\mathrm{SiN}_{x}$ layer. The value of $x$ was tuned in order to obtain a refractive index similar to $\mathrm{IOH}$, resulting in an equivalent optical cell configuration, but without free carrier absorption in the electrodes. We can see a further increase in cell reflectance in the near-infrared part of Fig. 5 resulting from the complete elimination of free carrier absorption in both front and back electrodes, so further current gains might be expected. As a result of the insulating nature of the $\mathrm{SiN}_{x}$ layers, it is obviously no longer possible to measure the EQE and we can therefore not determine the gain in current quantitatively. Inspection of the reflectance measurement on the cell with the $\mathrm{SiN}_{x}$ electrodes in Fig. 5 reveals that there is still a significant amount of light $(>20 \%)$, which is absorbed within the bandgap of $\mu \mathrm{c}-\mathrm{Si}: \mathrm{H}$ above $1100 \mathrm{~nm}$. To understand this contribution to the parasitic absorption, we further eliminated the doped silicon layers in the cell and finally observe that almost $95 \%$ of the incoming light is reflected back out of the

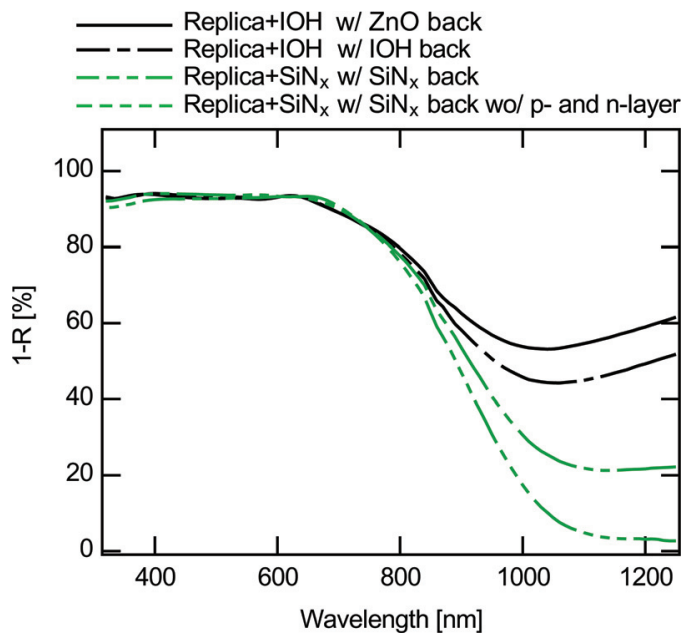

FIG. 5. (Color online) Optical reflectance $1-R$ measurements of micromorph solar cells on replicated $\mathrm{ZnO}$ morphology. For ease of comparison the measurement of Fig. 2 with $\mathrm{IOH}$ at the front electrode and $\mathrm{ZnO}$ at the back electrode is shown again. In addition we show the reflectance measurement on the cells with $\mathrm{IOH}$ front and back electrodes, with $\mathrm{SiN}_{x}$ front and back insulating electrodes, and $\mathrm{SiN}_{x}$ front and back insulating electrodes without the doped p- and n-silicon layers. All measurements were carried out with the white diffuse back reflector. cell. Therefore we conclude that, besides the electrodes, the doped layers also contribute significantly to parasitic absorption in the near-infrared part of the spectrum. However, one should not forget that the elimination of the free carrier absorption in the electrodes leads to an increase of the light path in the cell, which in turn leads to an overestimation of the contribution of the doped layers to parasitic absorption.

As we eliminated at this point all accessible sources of parasitic absorption in the cell, i.e., the contributions of the electrodes and the doped layers, we can now compare the resulting reflectance with the corrected $E \tilde{Q} E$, shown in Fig. 6 . We see that $1-R$ and $E \tilde{Q} E$ almost coincide, demonstrating the internal consistency of the two methods. Our approach therefore allows one to relate the optical measurement to the electrical measurement and represents a useful tool for comparing the light trapping capacities of different textures. This can be done by a simple reflectance measurement on the cell stack avoiding troubles with electrical properties of the cells, which may eventually be solved by adapting the layer properties to the new morphology.

As the results of the optical measurements with $\mathrm{SiN}_{x}$ electrodes prove, additional current gains are possible by reducing the free carrier absorption in the electrodes further. Of course, this becomes increasingly difficult, as the already extraordinarily high mobility of $\mathrm{IOH}$ must be improved to maintain an acceptable material resistivity. Koida et al. ${ }^{28}$ showed that the Hall mobility for $\mathrm{IOH}$ (taking into account carrier transport across grain boundaries) is almost identical to its optical mobility (which represents only intragrain transport). Consequently, efforts to improve $\mathrm{IOH}$ further must address the material quality inside the grains. A similar situation is encountered for $\mathrm{ZnO}$, for which Steinhauser et $a l{ }^{34}$ observed that the Hall mobility converges toward the value of the optical mobility $\left(38 \mathrm{~cm}^{2} / \mathrm{V} \cdot \mathrm{s}\right)$, when the grain size is increased by growing thicker films (i.e., the density of grain boundaries is reduced), ${ }^{34}$ concluding that efforts to improve film quality by increasing the grain size beyond this

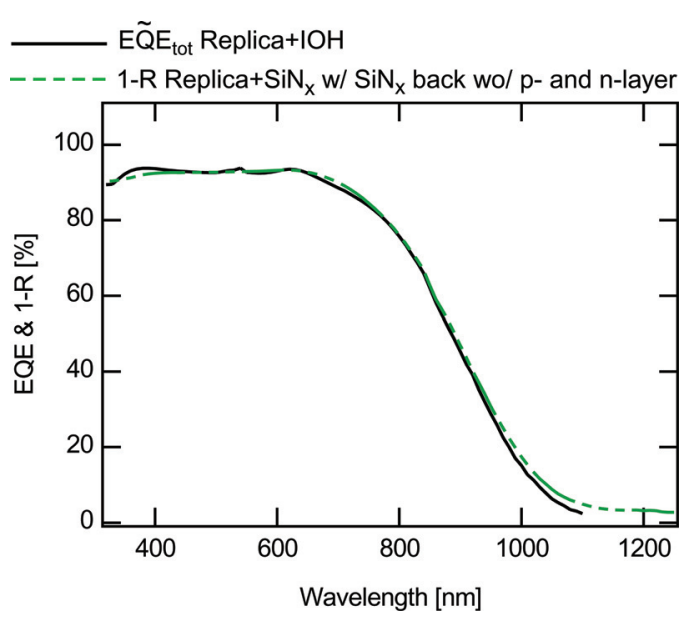

FIG. 6. (Color online) Optical reflectance $1-R$ measurement for the micromorph solar cell on replicated $\mathrm{ZnO}$ morphology with $\mathrm{SiN}_{x}$ front and back insulating electrodes without the doped p- and n-silicon layers. The corrected total $E \tilde{Q} E$ for the micromorph solar cell on replicated $\mathrm{ZnO}$ morphology with InO front electrode. The $1-R$ and $E \tilde{Q} E$ measurement almost coincide as parasitic absorption has almost completely been eliminated. 
value are useless. However, recent efforts in our lab to improve the quality inside the grains allowed us to achieve mobilities above $50 \mathrm{~cm}^{2} / \mathrm{V} \cdot \mathrm{s}$ for LP-CVD $\mathrm{ZnO}$.

$\mathrm{IOH}$ in combination with a replicated nanotextured substrate proves to be an excellent choice with respect to the optical properties. Substantial current gains in top and bottom cell with respect to state-of-the-art $\mathrm{ZnO}$ substrates may be achieved. When considering the electrical properties such as open-circuit voltage $V_{o c}$ and fill factor $F F$ listed in Table II, however, we observe some drawbacks. With respect to the bare $\mathrm{ZnO}$ substrate, the $V_{o c}$ of cells on IOH and ITO based electrodes is $10-26 \mathrm{mV}$ lower. Similarly the $F F$ is lower by $1-4 \%$. The lower $F F$, which reflects resistive losses in the cell, can be explained partially by the higher sheet resistance of the IOH and ITO electrodes with respect to $\mathrm{ZnO}$. But this explains neither the reduction in $V_{o c}$ nor the reduced $F F$ of the cells on $\mathrm{IOH}$-covered $\mathrm{ZnO}$, which has the same sheet resistance as bare $\mathrm{ZnO}$. It has been shown that porous areas between grain agglomerates in the microcrystalline silicon layer, known as cracks, caused by the growth dynamics on rough substrates, are detrimental for both $V_{o c}$ and $F F$ because they act as local current drains. ${ }^{35}$ Much effort has been devoted to adapting the morphology of $\mathrm{ZnO}$ by plasma surface treatments ${ }^{23}$ to avoid such cracks, by going from " $\vee$ "-shaped valleys to " $U$ "-shaped valleys. However, adding a sputtered layer on top of a topography with " $U$ "-shaped valley and sharp " $\wedge$ "-shaped crests, the crests have the tendency to get smoothed and become " $\cap$ "-shaped, while the " $U$ "-shaped valleys turn into " $V$ "-shapes. With the resulting pinches at the bottom of the valleys, the tendency for the creation of cracks in the microcrystalline layer becomes increasingly acute. These pinches become more and more narrow and therefore problematic at higher IOH or ITO coverage. The thickness of the amorphous silicon layer is also of importance, as it influences the topography in a similar way as the sputtered IOH and ITO layers. However a minimal IOH or ITO thickness is mandatory to maintain a sufficiently low sheet resistance in order to avoid Ohmic losses in the front contact, which in turn also reduce the $F F$. To further improve the efficiency of micromorph solar cells with $\mathrm{IOH}$ electrodes in the future, the surface topology of the master used for replication must be adapted to take into account the modification of the morphology imposed by the sputtered IOH film in order to guarantee optimum conditions for the growth of the microcrystalline silicon layers. It remains one of the major challenges of thin-film solar cells to find an optimal morphology that maximizes light trapping while maintaining high electrical performance. Promising recent developments toward more morphology-tolerant silicon layers, ${ }^{29,30,36}$ combined with the flexibility of nanoimprinting and the high infrared transparency of $\mathrm{IOH}$, provide a clear roadmap for the integration of even more aggressive nanostructures into micromorph solar cells.

\section{CONCLUSION}

We presented an extensive optical comparison of front electrodes for micromorph thin-film silicon solar cells based on sputtered IOH and ITO electrodes and state-of-the-art
$\mathrm{ZnO}$ electrodes fabricated via chemical vapor deposition. In order to achieve light trapping with IOH and ITO based electrodes, we replicated the random pyramidal morphology of $\mathrm{ZnO}$ using UV-NIL. We find that a substantial gain in shortcircuit current density of $1.9 \mathrm{~mA} / \mathrm{cm}^{2}$ may be achieved by replacing $\mathrm{ZnO}$ with $\mathrm{IOH}$. Gains in the near-infrared part are due to the very low free carrier absorption of $\mathrm{IOH}$ resulting from its extraordinarily high mobility. Gains are also observed in the blue part of the solar spectrum, which are related to the higher bandgap of $\mathrm{IOH}$ with respect to $\mathrm{ZnO}$. We presented an in-depth comparison of the light scattering capacities of these electrodes and estimated the losses due to parasitic absorption in the cell. Using nonabsorbing insulating $\mathrm{SiN}_{x}$ electrodes on the replica, we further presented a method to relate optical reflectance measurements to the electrical EQE measurements and showed that additional current gains in the near-infrared are possible. Our work also shows that the doped silicon layers contribute significantly to parasitic absorption in the near-infrared part of the spectrum. We further discussed the electrical properties of the cell and their relation to substrate morphology.

\section{ACKNOWLEDGMENTS}

We acknowledge Peter Cuony and Takashi Koida for fruitful discussions, Roth \& Rau Switzerland for financing the IOH target and the Swiss Federal Energy Office and the Swiss National Science Foundation for funding under project no. 101191 and grant no. 200021 12577/1.

\footnotetext{
${ }^{1}$ A. Shah, Thin-film silicon solar cells (EPFL Press, CRC Press, 2010).

${ }^{2}$ A. G. Aberle, Thin Solid Films 517, 4706 (2009).

${ }^{3}$ J. Meier, S. Dubail, D. Fischer, J. A. A. Selvan, N. P. Vaucher, R. Platz, C. Hof, R. Flückiger, U. Kroll, N. Wyrsch, P. Torres, H. Keppner, A. Shah, and K.-D. Ufert, Proceedings of the 13th European Photovoltaic Solar Energy Conference, Nice, France, 1445 (1995).

${ }^{4}$ C. Battaglia, J. Escarré, K. Söderström, L. Erni, L. Ding, G. Bugnon, A. Billet, M. Boccard, L. Barraud, S. D. Wolf, F.-J. Haug, M. Despeisse, and C. Ballif, Nano Lett. 11, 661 (2010).

${ }^{5}$ J. J. Hanak, Solar Energy 23, 145 (1979).

${ }^{6}$ M. Boccard, P. Cuony, C. Battaglia, M. Despeisse, and C. Ballif, Phys. Status Solidi (RRL) 4, 326 (2010).

${ }^{7}$ S. Nicolay, M. Despeisse, F.-J. Haug, and C. Ballif, Sol. Energy Mater. Sol Cells 95, 1031 (2011).

${ }^{8}$ H. Zhu, J. Hüpkes, E. Bunte, A. Gerber, and S. M. Huang, Thin Solid Films 518, 4997 (2010).

${ }^{9}$ W. Zhang, E. Bunte, J. Worbs, H. Siekmann, J. Kirchhoff, A. Gordijn, and J. Hüpkes, Phys. Status Solidi C 7, 1120 (2010).

${ }^{10}$ K. Jäger, O. Isabella, L. Zhao, and M. Zeman, Phys. Status Solidi C 3, 945 (2010).

${ }^{11}$ A. Hongsingthong, T. Krajangsang, I. A. Yunaz, S. Miyajima, and M. Konagai, Appl. Phys. Express 3, 051102 (2010).

${ }^{12}$ T. Koida, H. Sai, and M. Kondo, Thin Solid Films 518, 2930 (2010).

${ }^{13}$ H. M. Yates, P. Evans, D. W. Sheel, and M. Vanecek, Thin Solid Films 519, 1334 (2010).

${ }^{14}$ C. Rockstuhl, S. Fahr, K. Bittkau, T. Beckers, R. Carius, F.-J. Haug, T. Söderström, C. Ballif, and F. Lederer, Opt. Express 18, A335 (2010).

${ }^{15}$ C. Battaglia, K. Söderström, J. Escarré, F.-J. Haug, D. Dominé, P. Cuony, M. Boccard, G. Bugnon, C. Denizot, M. Despeisse, A. Feltrin, and C. Ballif, Appl. Phys. Lett. 96, 213504 (2010).

${ }^{16}$ D. Dominé, F.-J. Haug, C. Battaglia, and C. Ballif, J. Appl. Phys. 107, 044504 (2010).

${ }^{17}$ M. Berginski, J. Hüpkes, W. Reetz, B. Rech, and M. Wuttig, Thin Solid Films 516, 5836 (2008).

${ }^{18}$ T. Koida, H. Fujiwara, and M. Kondo, Jpn. J. Appl. Phys. 46, L685 (2007).
} 
${ }^{19}$ T. Koida, H. Fujiwara, and M. Kondo, Appl. Phys. Express 1, 041501 (2008).

${ }^{20}$ S. Faÿ, J. Steinhauser, N. Oliveira, E. Vallat-Sauvain, and C. Ballif, Thin Solid Films 515, 8558 (2007).

${ }^{21}$ M. Kambe, M. Fukawa, N. Taneda, Y. Yoshikawa, K. Sato, K. Ohki, S. Hiza, A. Yamada, and M. Konagai, Proceedings of the 3rd World Conference on Photovoltaic Energy Conversion, Osaka, Japan, 1812 (2003).

${ }^{22}$ J. Escarré, K. Söderström, F.-J. Haug, C. Battaglia, and C. Ballif, Sol. Energy Mater. Sol Cells 95, 881 (2011).

${ }^{23}$ J. Bailat, D. Dominé, R. Schlüchter, J. Steinhauser, S. Faÿ, F. Freitas, C. Bucher, L. Feitknecht, X. Niquille, T. Tscharner, A. Shah, and C. Ballif, Proceedings of the 4th World Conference on Photovoltaic Energy Conversion, Waikoloa, Hawaii, 1533 (2006).

${ }^{24}$ K. Söderström, J. Escarré, O. Cubero, F.-J. Haug, S. Perregaux, and C. Ballif, Prog. Photovoltaics: Res. Appl., 19, 202 (2011).

${ }^{25}$ M. Kitagawa, K. Mori, S. Ishihara, M. Ohno, T. Hirao, Y. Yoshioka, and S. Kohiki, J. Appl. Phys. 54, 3269 (1983).

${ }^{26}$ S. Kumar and B. Drevillon, J. Appl. Phys. 65, 3023 (1989).

${ }^{27}$ H. Fujiwara, M. Kondo, and A. Matsuda, J. Appl. Phys. 93, 2400 (2003).
${ }^{28}$ T. Koida, M. Kondo, K. Tsutsumi, A. Sakaguchi, M. Suzuki, and H. Fujiwara, J. Appl. Phys. 107, 033514 (2010).

${ }^{29}$ M. Despeisse, G. Bugnon, A. Feltrin, M. Stueckelberger, P. Cuony, F. Meillaud, A. Billet, and C. Ballif, Appl. Phys. Lett. 96, 073507 (2010).

${ }^{30}$ M. Despeisse, M. Boccard, G. Bugnon, P. Cuony, T. Söderström, G. Parascandolo, M. Stückelberger, M. Charriere, L. Löfgren, C. Battaglia, S. Hänni, A. Billet, F. Meillaud, and C. Ballif, Proceedings of the 5th World Conference on Photovoltaic Energy Conversion, Valencia, Spain, 2793 (2010).

${ }^{31}$ P. Buehlmann, J. Bailat, D. Dominé, A. Billet, F. Meillaud, A. Feltrin, and C. Ballif, Appl. Phys. Lett. 91, 143505 (2007).

${ }^{32}$ M. Berginski, J. Hüpkes, M. Schulte, G. Schöpe, H. Stiebig, B. Rech, and M. Wuttig, J. Appl. Phys. 101, 074903 (2007)

${ }^{33}$ D. Dominé, Ph.D. thesis, Université de Neuchatel, 2009.

${ }^{34}$ J. Steinhauser, S. Faÿ, N. Oliveira, E. Vallat-Sauvain, and C. Ballif, Appl. Phys. Lett. 90, 142107 (2007).

${ }^{35}$ M. Python, O. Madani, D. Dominé, F. Meillaud, E. Vallat-Sauvain, and C. Ballif, Sol. Energy Mater. Sol. Cells 93, 1714 (2009).

${ }^{36}$ P. Cuony, M. Marending, D. T. L. Alexander, M. Boccard, G. Bugnon, M. Despeisse, and C. Ballif, Appl. Phys. Lett. 97, 213502 (2010). 